\title{
Multiresonant Frequency-Locked Loop for Grid Synchronization of Power Converters Under Distorted Grid Conditions
}

\author{
Pedro Rodríguez, Senior Member, IEEE, Alvaro Luna, Student Member, IEEE, Ignacio Candela, Member, IEEE, \\ Ramon Mujal, Member, IEEE, Remus Teodorescu, Senior Member, IEEE, and Frede Blaabjerg, Fellow, IEEE
}

\begin{abstract}
This paper presents a new multiresonant frequencyadaptive synchronization method for grid-connected power converters that allows estimating not only the positive- and negative-sequence components of the power signal at the fundamental frequency but also other sequence components at other harmonic frequencies. The proposed system is called MSOGI-FLL since it is based on both a harmonic decoupling network consisting of multiple second-order generalized integrators (MSOGIs) and a frequency-locked loop (FLL), which makes the system frequency adaptive. In this paper, the MSOGI-FLL is analyzed for singleand three-phase applications, deducing some key expressions regarding its stability and tuning. Moreover, the performance of the MSOGI-FLL is evaluated by both simulations and experiments to show its capability for detecting different harmonic components in a highly polluted grid scenario.
\end{abstract}

Index Terms-Frequency estimation, frequency-locked loops (FLLs), harmonic analysis, monitoring, synchronization.

\section{INTRODUCTION}

$\mathbf{T}$ HE CLASSICAL electricity infrastructure, typically consisting of large and centralized power generation facilities linked to the final consumers, has been turning toward a distributed power generation system, where renewable energies are becoming important players. In this distributed scenario, the electricity networks of the future will make extensive use of power electronic devices and information and communication technology applications [1], [2] as an interface between the generation systems and the electricity network. Accordingly, the grid-connected power converters used in distributed power generation systems should be carefully designed and controlled to achieve an optimal and efficient operation [3]-[10].

Manuscript received June 25, 2009; revised November 13, 2009; accepted January 2, 2010. Date of publication April 12, 2010; date of current version December 10, 2010. This work was supported by the Spanish Ministry of Science and Innovation under Project ENE2008-06841-C02-01/ALT.

P. Rodríguez, A. Luna, I. Candela, and R. Mujal are with the Department of Electrical Engineering, Technical University of Catalonia, 08222 Barcelona, Spain(e-mail: prodriguez@ee.upc.edu; luna@ee.upc.edu; candela@ee.upc. edu;mujal@ee.upc.edu).

R. Teodorescu is with the Department of Energy Technology, Aalborg University, 9220 Aalborg East, Denmark, and also with the Department of Electrical Engineering, University of Galati, Galati 800008, Romania (e-mail: ret@iet.aau.dk).

F. Blaabjerg is with the Department of Energy Technology, Aalborg University, 9220 Aalborg East, Denmark (e-mail: fbl@ iet.aau.dk).

Color versions of one or more of the figures in this paper are available online at http://ieeexplore.ieee.org.

Digital Object Identifier 10.1109/TIE.2010.2042420
One of the most important issues in the connection of power converters to the grid is the synchronization with the voltage at the point of common coupling (PCC). Grid-connected converters should properly be synchronized with the grid to stay actively connected, supporting the grid services (voltage/ frequency) and keeping the generation up even if the voltage at its PCC is distorted and unbalanced. The phase-locked loop (PLL) technology has been used for decades in communications, military, and aerospace systems to synchronize a local oscillator with some recognizable external signal. Following these examples, a grid-connected power converter can also use a PLL to synchronize its internal control system to the grid voltage or current [11]-[14]. In three-phase systems, PLLs based on a synchronous reference frame (SRF-PLL) [15] have become a conventional synchronization technique [16], [17]. Although these systems have been shown to be fast and accurate under balanced conditions, their response is unacceptably deficient when the utility voltage is unbalanced. This is a serious drawback for SRF-PLLs as the voltage waveforms are prone to be distorted and unbalanced as a consequence of the effect of nonlinear loads and assymetrical grid faults [18]-[20].

Different advanced synchronization systems able to deal with these grid conditions have been proposed in the literature as an alternative to SRF-PLL. For instance, the decoupled double SRF-PLL presented in [21] overcomes the aforementioned drawback by using two SRFs and a decoupling network to isolate the effects of the positive- and negative-sequence voltage components. Another interesting synchronization technique was published in [22]-[24], where three single-phase enhanced PLLs were combined with a positive-sequence calculator to synchronize with unbalanced and polluted three-phase networks without using any SRF.

Other advanced synchronization structures based on using a frequency-locking concept instead of the conventional phaselocking one have been proposed as well. As shown in [15], PLLs synchronize with the phase of the input signal, and hence, the accuracy and dynamical response of its estimation under transient conditions are highly influenced by phaseangle jumps. On the other hand, a frequency-locked loop (FLL) estimates the frequency of the input signal, which does not experience such sudden changes. As a consequence, the performance of the FLL when the phase angle of the input changes is more advantageous if compared with PLL-based algorithms. 
A similar approach to [22], but using a frequency-locking concept instead of the conventional phase-locking one, was presented in [25]. In this case, a system based on a dual secondorder generalized integrator resting on an FLL (DSOGI-FLL) was proven to be an effective solution under adverse grid conditions.

Although these advanced synchronization systems are capable of making an accurate estimation of the fundamental components of the voltage under unbalanced conditions, they are unable to perform a more precise characterization of the power signals, something that is necessary in those applications where voltage and/or voltage harmonic components should be computed and, in certain cases, controlled as well.

Regarding this topic, a rigorous analysis of three algorithms for the real-time decomposition of power signals in multiple SRFs based on PLLs, recursive discrete Fourier transform (RDFT), and discrete Kalman filtering (DKF), respectively, was presented in [26]. Another interesting review of harmonic estimation methods on both frequency and time domains for active filtering applications was presented in [27].

Solutions based on the application of parallel adaptive notch filters for estimating multiple frequencies have also been recently proposed [28]-[31]. A single-phase application based on such technique was described in [28], where the proposed estimation algorithm does not compute any phase angle, being a direct frequency-adaptive estimation system. This approach was later applied to three phase systems, as shown in [29]-[31].

This paper proposes a new technique for detecting multiple positive-/negative-sequence frequency harmonics in threephase systems by using an extended approach to that presented in [22]. The proposed system has been named as MSOGI-FLL since it is based on multiple second-order generalized integrators (MSOGIs) working together inside a harmonic decoupling network (HDN), which is frequency adaptive thanks to the use of an FLL.

As a difference with RDFT or DKF applications, the presented system permits to instantaneously estimate the symmetrical components of the harmonics in a three-phase system without significantly increasing the processing time. In addition, the MSOGI-FLL results in a lighter computation algorithm if compared with the previous ones, based on a simple and understandable structure that is easy to be tuned in function of the performance requirement. Moreover, the resulting system can easily be programmed in low-cost DSP platforms.

In the following, the main building blocks of the MSOGIFLL will be presented, paying special attention on the description of the second-order generalized integrator (SOGI) and the FLL and their application for three-phase systems. Finally, the performance of the proposed synchronization method is evaluated by both simulations and experiments.

\section{SOGI-FLL}

The concept of the generalized integrator (GI) for sinusoidal signals was formally presented in [32]. This integrator stems from the principle that the time-domain convolution product of a sinusoidal function by itself gives rise to the original function

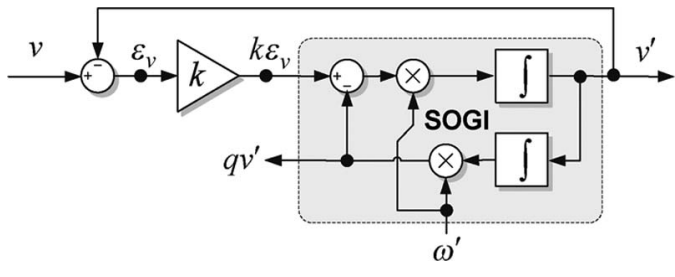

Fig. 1. Adaptive filter based on SOGI, i.e., SOGI-QSG.

multiplied by the time variable. Therefore, a processing block whose transfer function matches with the Laplace transform of a sinusoidal function, i.e., a resonator, will act as an "amplitude integrator" for a sinusoidal signal applied to its input. Moreover, the in-quadrature combination of the sine and cosine transfer functions gives rise to an "ideal integrator" independent of the phase angle of the sinusoidal input signal. In [32], a simplified block with a transfer function given by $2 s /\left(s^{2}+\omega^{2}\right)$ was presented as a GI for single sinusoidal signals.

The GI is the base of proportional-resonant controllers [33]-[36], and it has also been applied to adaptive filtering applications and PLL implementation [37]. An adaptive filter structure, based on the GI structure, named SOGI was presented in [38] and [39]. The structure of this filter is shown in Fig. 1, where it can be noticed how the resonance frequency of the SOGI is an external parameter called $\omega^{\prime}$.

The transfer function of the SOGI is given by

$$
\operatorname{SOGI}(s)=\frac{v^{\prime}}{k \varepsilon_{v}}(s)=\frac{\omega^{\prime} s}{s^{2}+\omega^{\prime 2}}
$$

where the resonance frequency was called $\omega^{\prime}$ to difference it from the input frequency $\omega$.

The two in-quadrature output signals of the adaptive filter in Fig. 1, i.e., $v^{\prime}$ and $q v^{\prime}$, are defined by the following transfer functions:

$$
\begin{aligned}
& D(s)=\frac{v^{\prime}}{v}(s)=\frac{k \omega^{\prime} s}{s^{2}+k \omega^{\prime} s+\omega^{\prime 2}} \\
& Q(s)=\frac{q v^{\prime}}{v}(s)=\frac{k \omega^{\prime 2}}{s^{2}+k \omega^{\prime} s+\omega^{\prime 2}} .
\end{aligned}
$$

As it can be concluded from (2a), the bandwidth of the bandpass filter is exclusively set by the gain $k$ and is independent of the center frequency $\omega^{\prime}$. The same happens with the low-pass filter of (2b), in which the static gain only depends on $k$.

The effect of the gain $k$ in the frequency response of the adaptive filter is clear in the Bode diagrams of Fig. 2. From these plots, it can be concluded that the $q v^{\prime}$ output is always $90^{\circ}$ lagged from the $v^{\prime}$ output. For this reason, the adaptive filter in Fig. 1 was named as SOGI quadrature signal generator (SOGI-QSG). This system, together with the FLL presented as follows, constitute the main building blocks of the synchronization algorithm presented in this paper.

\section{A. FLL}

The FLL was presented in [25] as an effective mechanism for adapting the center frequency of the SOGI-QSG. The adaptive filter, including the FLL, is shown in Fig. 3. 


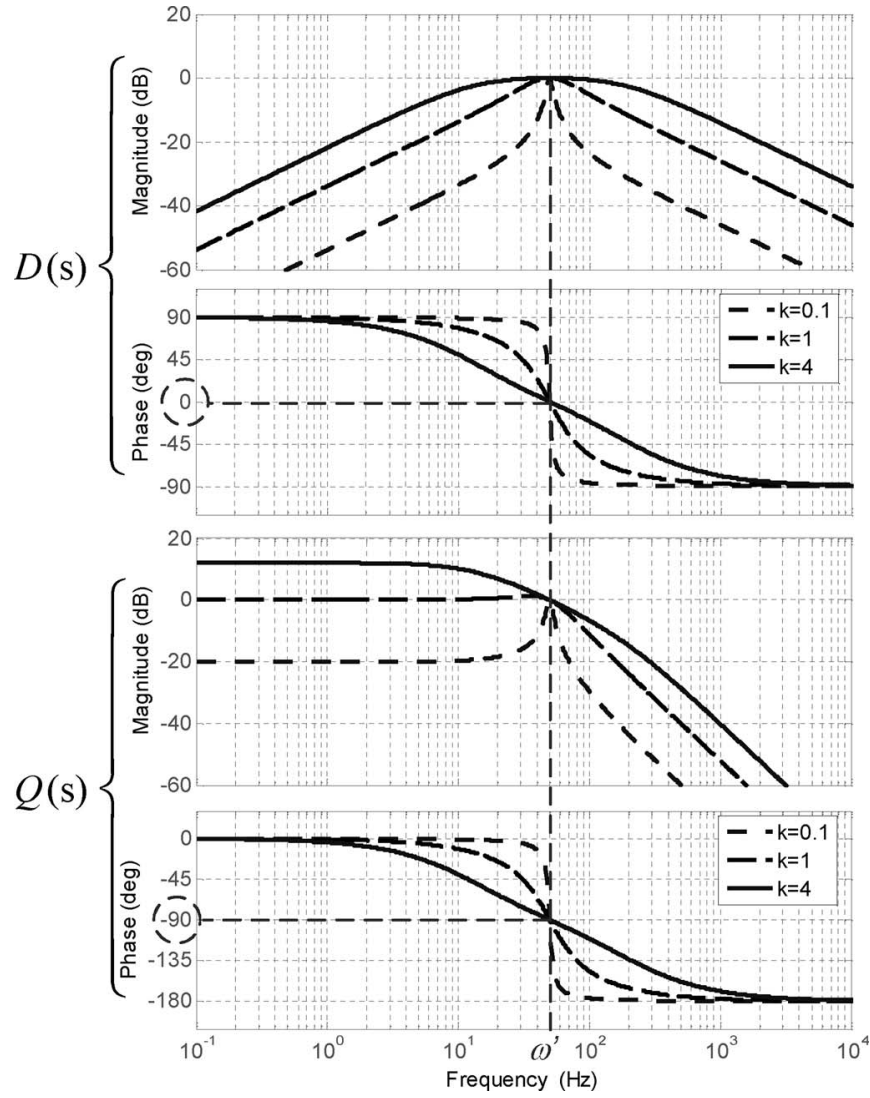

Fig. 2. Bode diagrams of the adaptive filter based on SOGI considering different values of $k$.

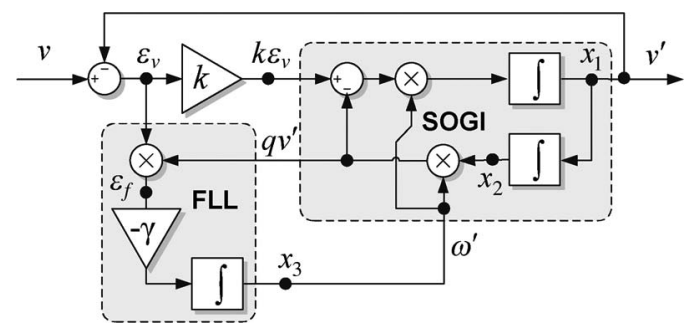

Fig. 3. SOGI-FLL, a single-phase grid synchronization system.

The transfer function from the input signal $v$ to the error signal $\varepsilon_{v}$, i.e., $E(s)$, is given by

$$
E(s)=\frac{\varepsilon_{v}}{v}(s)=\frac{s^{2}+\omega^{\prime 2}}{s^{2}+k \omega^{\prime} s+\omega^{\prime 2}} .
$$

Likewise, the relationship between $v$ and $q v^{\prime}$, i.e., $Q(s)$, was detailed in (2b).

Both $Q(s)$ and $E(s)$ are plotted together in the Bode diagram of Fig. 4. It can be observed from the diagram that the signals $q v^{\prime}$ and $\varepsilon_{v}$ are in phase when the input frequency is lower than the SOGI resonance frequency $\left(\omega<\omega^{\prime}\right)$, and they are in counter phase when $\omega>\omega^{\prime}$. Therefore, a frequency error variable $\varepsilon_{f}$ can be defined as the product of $q v^{\prime}$ by $\varepsilon_{v}$. As shown in the Bode diagram of Fig. 4, the average value of $\varepsilon_{f}$ will be positive when $\omega<\omega^{\prime}$, zero when $\omega=\omega^{\prime}$, and negative when $\omega>\omega^{\prime}$. Hence, as shown in Fig. 3, an integral controller with a negative gain $-\gamma$ can be used to make zero the dc com-

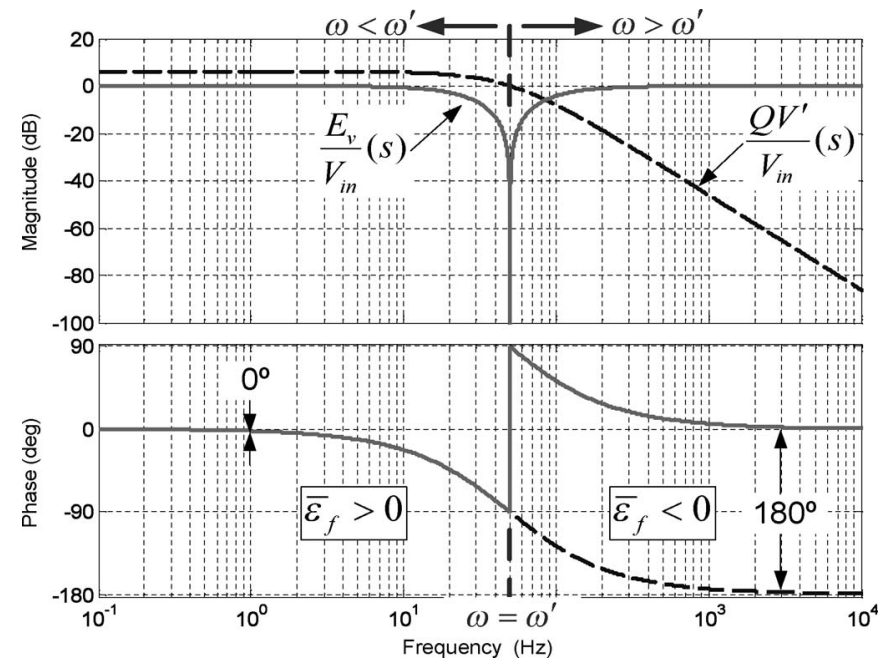

Fig. 4. Bode diagram of the FLL input variables.

ponent of the frequency error by shifting the SOGI resonance frequency $\omega^{\prime}$ until matching the input frequency $\omega$.

The SOGI-FLL shown in Fig. 3 is a single-phase synchronization system in which the input frequency is directly detected by the FLL, and the phase angle and amplitude of the input "virtual vector" $v$ can indirectly be calculated by

$$
\left|\vec{v}^{\prime}\right|=\sqrt{\left(v^{\prime}\right)^{2}+\left(q v^{\prime}\right)^{2}} \quad \mid \underline{\vec{v}^{\prime}}=\arctan \frac{q v^{\prime}}{v^{\prime}} .
$$

\section{Stability ANALysis AND TUNING OF SOGI-FLL}

The space-state equations of the SOGI-FLL can be obtained from the system in Fig. 3, where $\mathbf{x}$ in (5a) is the state vector of the SOGI, and $\mathbf{y}$ in (5b) is the output vector. The state equation describing the behavior of the FLL is also shown in (5c), i.e.,

$$
\begin{aligned}
\dot{\mathbf{x}} & =\mathbf{A} \mathbf{x}+\mathbf{B} v \Rightarrow\left[\begin{array}{l}
\dot{x}_{1} \\
\dot{x}_{2}
\end{array}\right] \\
& =\left[\begin{array}{cc}
-k \omega^{\prime} & -\omega^{\prime 2} \\
1 & 0
\end{array}\right]\left[\begin{array}{l}
x_{1} \\
x_{2}
\end{array}\right]+\left[\begin{array}{c}
k \omega^{\prime} \\
0
\end{array}\right] v \\
\mathbf{y} & =\mathbf{C x} \Rightarrow\left[\begin{array}{c}
v^{\prime} \\
q v^{\prime}
\end{array}\right]=\left[\begin{array}{cc}
1 & 0 \\
0 & \omega^{\prime}
\end{array}\right]\left[\begin{array}{l}
x_{1} \\
x_{2}
\end{array}\right] \\
\dot{\omega}^{\prime} & =-\gamma x_{2} \omega^{\prime}\left(v-x_{1}\right) .
\end{aligned}
$$

As it can be concluded from (5), the SOGI-FLL behaves as a nonlinear system, whose dynamical response, as well as its own stability, depends on four parameters, namely: the amplitude and frequency of the input signal and the values of $k$ and $\gamma$, which are the control parameters of the SOGI and the FLL, respectively.

Considering stable operating conditions, with $\dot{\omega}^{\prime}=0$ and $\omega=\omega^{\prime}$, (5a) gives rise to

$$
\dot{\overline{\mathbf{x}}}_{{\dot{\omega^{\prime}=0}}}=\left[\begin{array}{c}
\dot{\bar{x}}_{1} \\
\dot{\bar{x}}_{2}
\end{array}\right]=\left[\begin{array}{cc}
0 & -\omega^{\prime 2} \\
1 & 0
\end{array}\right]\left[\begin{array}{l}
\bar{x}_{1} \\
\bar{x}_{2}
\end{array}\right]
$$

in which the steady-state variables are written with a bar over them. 
The eigenvalues of the Jacobian obtained from (6) have a null real part, which confirms the resonant behavior of the system, remaining the steady-state response in a periodic orbit at the $\omega^{\prime}$ frequency. Therefore, for a given sinusoidal input signal $v=$ $V \sin (\omega t+\phi)$, the steady-state output vector will be given by

$$
\overline{\mathbf{y}}=\left[\begin{array}{c}
v^{\prime} \\
q v^{\prime}
\end{array}\right]=V\left[\begin{array}{c}
\sin (\omega t+\phi) \\
-\cos (\omega t+\phi)
\end{array}\right] .
$$

If the FLL was intentionally frozen at a frequency different from the input signal frequency $\left(\omega \neq \omega^{\prime}\right)$, e.g., by making $\gamma=0$, then the output vector would still keep in a stable orbit defined by

$$
\overline{\mathbf{y}}^{\prime}=V|D(j \omega)|\left[\begin{array}{c}
\sin (\omega t+\phi+\angle D(j \omega)) \\
-\frac{\omega^{\prime}}{\omega} \cos (\omega t+\phi+\angle D(j \omega))
\end{array}\right]
$$

where

$$
\begin{aligned}
& |D(j \omega)|=\frac{k \omega \omega^{\prime}}{\sqrt{\left(k \omega \omega^{\prime}\right)^{2}+\left(\omega^{2}-\omega^{\prime 2}\right)^{2}}} \\
& \angle D(j \omega)=\arctan \frac{\omega^{\prime 2}-\omega^{2}}{k \omega \omega^{\prime}} .
\end{aligned}
$$

\section{A. Local Stability}

It is possible to appreciate from (8) that the SOGI states keep the following steady-state relationship when a sinusoidal input signal at the frequency $\omega$ is applied to its input, even if $\omega \neq \omega^{\prime}$

$$
\dot{\bar{x}}_{1}=-\omega^{2} \bar{x}_{2} .
$$

Therefore, the steady-state synchronization error signal can be written from (5a) as

$$
\bar{\varepsilon}_{v}=\left(v-\bar{x}_{1}\right)=\frac{1}{k \omega^{\prime}}\left(\dot{\bar{x}}_{1}+\omega^{\prime 2} \bar{x}_{2}\right) .
$$

From (11) and (12), the steady-state frequency error signal is given by

$$
\bar{\varepsilon}_{f}=\omega^{\prime} \bar{x}_{2} \bar{\varepsilon}_{v}=\frac{\bar{x}_{2}^{2}}{k}\left(\omega^{\prime 2}-\omega^{2}\right) .
$$

Expression (13) corroborates that the signal $\varepsilon_{f}$ collects information about error in frequency estimation, and hence, it is suitable to act as the control signal of the FLL. An analysis about the local stability of the FLL can be conducted by considering $\omega^{\prime} \approx \omega$. In such a case, $\omega^{\prime 2}-\omega^{2}$ can be approximated as $2\left(\omega^{\prime}-\omega\right) \omega^{\prime}$, and the local dynamics of the FLL can be described by

$$
\dot{\omega}^{\prime}=-\gamma \bar{\varepsilon}_{f}=\frac{\gamma}{k} \bar{x}_{2}^{2}\left(\omega^{\prime 2}-\omega^{2}\right) \approx-2 \frac{\gamma}{k} \bar{x}_{2}^{2}\left(\omega^{\prime}-\omega\right) \omega^{\prime} .
$$

Defining the error in frequency estimation as $\sigma=\left(\omega^{\prime}-\omega\right)$, its derivative is given by $\dot{\sigma}=\dot{\omega}^{\prime}$ when the input frequency $\omega$ is considered a constant. Therefore, the condition

$$
\sigma \dot{\sigma}=-2 \frac{\gamma}{k} \bar{x}_{2}^{2} \sigma^{2} \omega^{\prime} \leq 0
$$

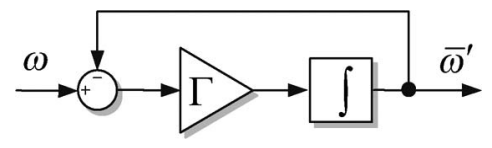

Fig. 5. Simplified frequency adaptation system of the FLL.

will always be true for positive values in the detected frequency $\omega^{\prime}$. This condition is the key for the local stabilization mechanism of the FLL.

\section{B. SOGI-QSG Tuning}

From the transfer functions in (2) and considering the input frequency $\omega$ as a constant, the time response of the SOGIQSG for a given sinusoidal input signal $v=V \sin (\omega t)$ is described by

$$
\begin{aligned}
v^{\prime}=- & \frac{V}{\lambda} \sin (\lambda \omega t) \cdot e^{-\frac{k \omega^{\prime}}{2} t}+V \sin (\omega t) \\
q v^{\prime}=V & {\left[\cos (\lambda \omega t)+\frac{k}{2 \lambda} \cdot \sin (\lambda \omega t)\right] e^{-\frac{k \omega^{\prime}}{2} t} } \\
& -V \cos (\omega t)
\end{aligned}
$$

where $\lambda=\sqrt{4-k^{2}} / 2$, and thus $k<2$.

Therefore, according to (16), the settle time in the SOGIQSG response can be approximated to

$$
t_{s(\mathrm{SOGI})}=\frac{10}{k \omega^{\prime}} .
$$

The value of $k$ determines the frequency bandwidth of the SOGI-QSG. A very high value of $k$ would make the SOGIQSG performance fast, reducing its immunity to the effects of harmonics in the input signal. On the contrary, a very low value for $k$ makes the SOGI-QSG very selective in frequency but gives rise to a long stabilization time. Considering these constrains, the gain of the SOGI-QSG is set to $k=\sqrt{2}$, which results in an optimal tradeoff between settle time, overshooting, and harmonic rejection.

\section{FLL Tuning}

Linear control analysis techniques cannot directly be applied to set the value of the FLL gain $\gamma$ since the frequency adaptation loop is highly nonlinear. As was demonstrated in [40], the averaged dynamics of the FLL with $\omega^{\prime} \approx \omega$ can be described by

$$
\dot{\bar{\omega}}^{\prime}=-\frac{\gamma V^{2}}{k \omega^{\prime}}\left(\bar{\omega}^{\prime}-\omega\right)
$$

where $\omega$ and $\omega^{\prime}$ are the actual and estimated frequencies, respectively, $\gamma$ is the FLL gain, and $V$ is the amplitude of the input signal.

From (18), the value of $\gamma$ can be normalized according to

$$
\gamma=\frac{k \omega^{\prime}}{V^{2}} \Gamma
$$

to obtain the feedback-based linearized system shown in Fig. 5, which is nondependent on neither the grid variables nor the SOGI-QSG gain. 


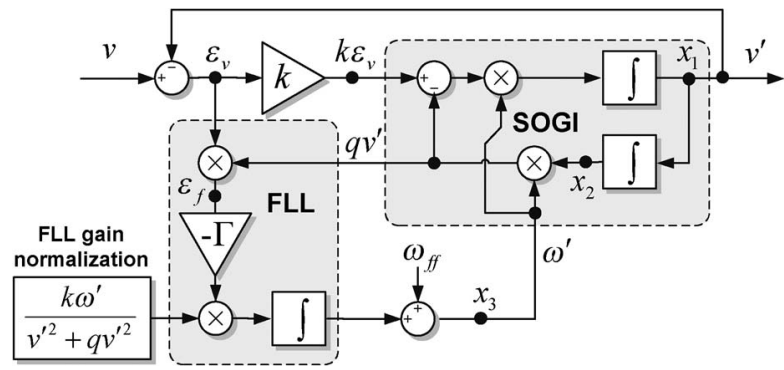

Fig. 6. SOGI-FLL with feedback-based FLL gain normalization.

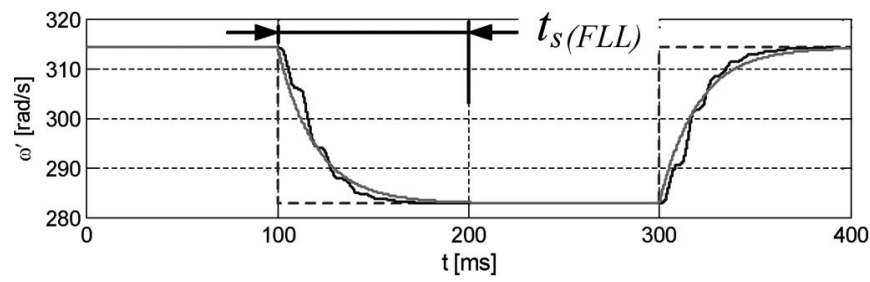

Fig. 7. Time response of FLL in presence of a frequency step.

The transfer function of the first-order frequency adaptation loop in Fig. 5 is given by

$$
\frac{\bar{\omega}^{\prime}}{\omega}=\frac{\Gamma}{s+\Gamma} .
$$

Therefore, the settle time is exclusively dependent on the design parameter $\Gamma$ and can be approximated by

$$
t_{s(\mathrm{FLL})} \approx \frac{5}{\Gamma}
$$

The feedback-based linearized FLL is depicted in Fig. 6, where (19) is represented by two independent blocks. The FLL gain normalization block computes the SOGI control parameter $k$ together with the output variables $\omega^{\prime}$ and $V^{2}=v^{\prime 2}+q v^{\prime 2}$ to linearize the response of the FLL. On the other hand, the time constant $\Gamma$ is the parameter that permits to set the dynamics of the frequency estimation.

Fig. 7 shows the time response of SOGI-FLL with $k=\sqrt{2}$ and $\Gamma=50$ when the frequency of the input signal suddenly varies from 50 to $45 \mathrm{~Hz}$. It can be appreciated in this figure that the detected frequency fits well a first-order exponential response with a settle time of $100 \mathrm{~ms}$, which matches with that calculated by (21).

\section{Multiple SOGI-FLL}

The SOGI-FLL is able to perform an accurate estimation of the fundamental component of the input voltage under generic operating conditions. Even in the presence of disturbances in the monitored input, it shows a remarkable capability for rejecting high-order harmonic components thanks to its inherent filtering characteristic. Nevertheless, certain characteristic loworder harmonics, like the third or the fifth, are very close to the fundamental frequency, and they lead to substantial distortion on the fundamental positive-negative sequence components detected by the SOGI-FLL.

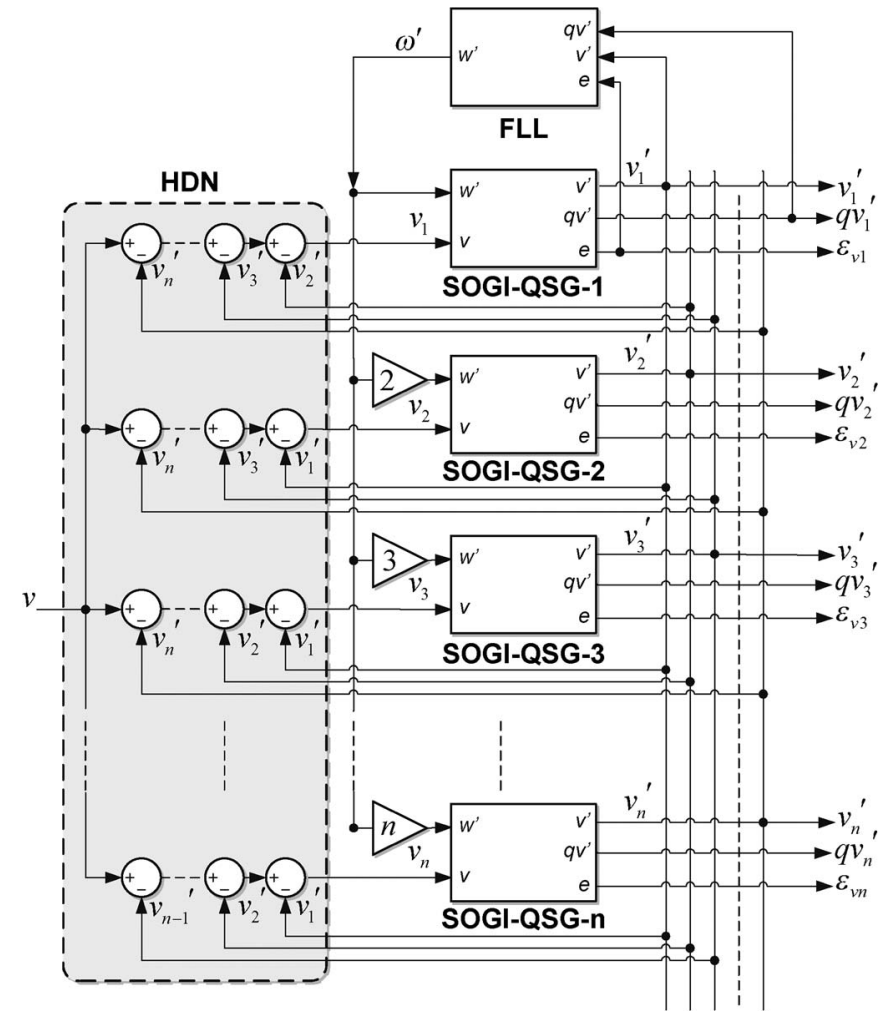

Fig. 8. Block diagram of MSOGI-FLL.

In this section, a cross-feedback network consisting of multiple SOGI-QSGs, like the one shown in Fig. 1, tuned at different frequencies, and working in a collaborative way, is presented as an effective solution to accurately detect the sequence components of the grid voltage, even under very extreme distortion conditions. This new estimation system will be referred from now on as multiple SOGI-FLL (MSOGI-FLL).

\section{A. Multiple Adaptive Filters}

The main structure of the MSOGI-FLL is presented in Fig. 8 . As it can be noticed from the figure, the MSOGI-FLL can be understood as a set of $n$ selective and adaptive filters, tuned at different frequencies and working in parallel. The FLL block is connected only to the SOGI-QSG-1 to detect the fundamental frequency of the input signal. Then, the estimated frequency is used to tune the frequency of each of the SOGI-QSGs by multiplying its value by a coefficient that determines the order of the harmonic to be detected by each SOGI-QSG. This structure thus permits to detect the different harmonic components of the input signal.

However, the accuracy of this estimation can highly be affected when the harmonic components are in a narrow range. For instance, the output of an adaptive filter tuned to the second harmonic (e.g., $100 \mathrm{~Hz}$ ) will partially be influenced by the fundamental component (e.g., $50 \mathrm{~Hz}$ ) because both frequency components are very close to each other. It would be necessary to set a very narrow bandwidth in the SOGI-QSGs to avoid these collateral effects, which would both make the system response too slow since it would be affected by additional transient oscillations. 


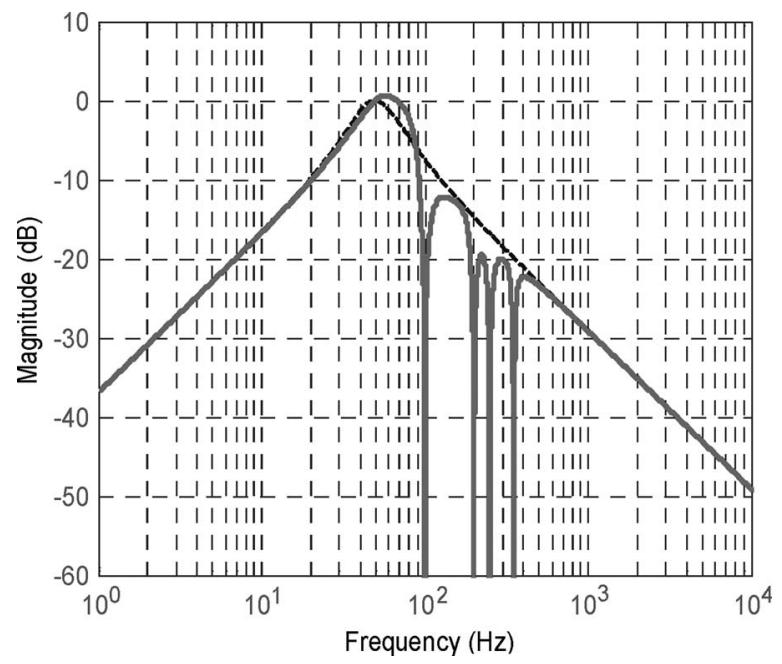

Fig. 9. Frequency response of the single-phase MSOGI-FLL.

\section{B. $H D N$}

To isolate the effect of the different harmonics of the input signal, the MSOGI-FLL uses HDN. As shown in Fig. 8, the HDN consists of a cross-feedback network, where $D_{i}(s)$ is a customized version of the transfer function shown in (2a), where the center frequency is given by $i \cdot \omega^{\prime}$, where $\omega^{\prime}$ is the fundamental frequency detected by the FLL, and $i$ is the harmonic order for the SOGI-QSG-i block, i.e.,

$$
v_{i}^{\prime}=D_{i}(s)\left(v-\sum_{\substack{j=1 \\ j \neq i}}^{n} v_{j}^{\prime}\right) .
$$

Another expression similar to (22) can be obtained for the $q v_{i}^{\prime}$ output of the SOGI-QSG- $i$ by using the $Q_{i}(s)$ transfer function from (2b). By developing the equations system resulting from (22) for an HDN with $n$ elements, the following transfer function can be obtained for the $v_{i}^{\prime}$ output of the MSOGI-QSG:

$$
v_{i}^{\prime}=\left[D_{i}(s) \prod_{\substack{j=1 \\ j \neq i}}^{n}\left(\frac{1-D_{j}(s)}{1-D_{i}(s) D_{j}(s)}\right)\right] v .
$$

As an example of the effect of the HDN, Fig. 9 shows the Bode diagram of the transfer function given by (23) for the $v_{1}^{\prime}$ output $(50 \mathrm{~Hz})$ of a MSOGI-FLL consisting of four SOGIQSGs tuned at the second, fourth, fifth, and seventh harmonics, respectively. The dashed line in Fig. 9 represents the frequency response curve for the case in which the HDN is disabled. It can be appreciated in this diagram how the HDN of the MSOGIFLL gives rise to notches in the frequency response curve at the frequencies where the individual SOGI-QSGs are tuned. As a consequence, the selective filtering characteristic of each SOGIQSG is improved, and its response is enhanced in case of high distortion level on the input voltage.

Despite the fact that in this section the behavior of the MSOGI was tested without considering the effects of interharmonics or subharmonics, it must be pointed out that the MSOGI is able to estimate such components as well just by adding another DSOGI block tuned at the proper frequency.

\section{MSOGI-FLL For Three-Phase ApPlications}

In this section, it will be shown how a three-phase MSOGIFLL can easily be implemented by applying the single-phase structure in Fig. 8 to the $v_{\alpha}$ and $v_{\beta}$ components of the threephase input vector but using a dual SOGI-QSG (DSOGI).

According to Lyon's method [41], [42], a voltage vector $v_{a b c}$ consisting of three unbalanced sinusoidal waveforms can be split up into its instantaneous positive-, negative-, and zerosequence components $\mathbf{v}_{a b c}=\mathbf{v}_{a b c}^{+}+\mathbf{v}_{a b c}^{-}+\mathbf{v}_{a b c}^{0}$ by applying the following transformations:

$$
\begin{aligned}
& \mathbf{v}_{a b c}^{+}=\left[T_{+}\right] \mathbf{v}_{a b c} \quad\left[\begin{array}{c}
v_{a}^{+} \\
v_{b}^{+} \\
v_{c}^{+}
\end{array}\right]=\frac{1}{3}\left[\begin{array}{ccc}
1 & a & a^{2} \\
a^{2} & 1 & a \\
a & a^{2} & 1
\end{array}\right]\left[\begin{array}{l}
v_{a} \\
v_{b} \\
v_{c}
\end{array}\right] \\
& \mathbf{v}_{a b c}^{-}=\left[T_{-}\right] \mathbf{v}_{a b c} \quad\left[\begin{array}{c}
v_{a}^{-} \\
v_{b}^{-} \\
v_{c}^{-}
\end{array}\right]=\frac{1}{3}\left[\begin{array}{ccc}
1 & a^{2} & a \\
a & 1 & a^{2} \\
a^{2} & a & 1
\end{array}\right]\left[\begin{array}{l}
v_{a} \\
v_{b} \\
v_{c}
\end{array}\right] \\
& \mathbf{v}_{a b c}^{0}=\left[T_{0}\right] \mathbf{v}_{a b c} \quad\left[\begin{array}{l}
v_{a}^{0} \\
v_{b}^{0} \\
v_{c}^{0}
\end{array}\right]=\frac{1}{3}\left[\begin{array}{ccc}
1 & 1 & 1 \\
1 & 1 & 1 \\
1 & 1 & 1
\end{array}\right]\left[\begin{array}{l}
v_{a} \\
v_{b} \\
v_{c}
\end{array}\right]
\end{aligned}
$$

where $a=e^{j(2 \pi / 3)}$ represents the Fortescue phase-shifting operator applied over the instantaneous input signals. In spite of the unbalance degree of the input, the symmetrical components give rise to a set of three phase-balanced and $120^{\circ}$-shifted signals for the positive- and negative-sequence components plus a third-component zero-sequence one whose three phase waveforms have the same amplitude and phase.

Considering that most of the three-phase grid-connected power converters employ a three-wire connection, it is only necessary to be synchronized with the positive- and negativesequence components of the grid voltage. This feature permits to transform the grid voltage vector from the $a b c$ to the $\alpha \beta$ stationary reference frames by using the Clarke transformation, as indicated in (25).

In turn, the instantaneous positive- and negative-sequence voltage components on the $\alpha \beta$ reference frame can be calculated as shown in (26), where $q=e^{-j(\pi / 2)}$ is a $90^{\circ}$-lagging phase-shifting operator applied on the time domain to obtain an in-quadrature version of the input waveforms

$$
\begin{aligned}
\mathbf{v}_{\alpha \beta} & =\left[T_{\alpha \beta}\right] \mathbf{v}_{a b c} \quad\left[T_{\alpha \beta}\right]=\sqrt{\frac{2}{3}}\left[\begin{array}{ccc}
1 & -\frac{1}{2} & -\frac{1}{2} \\
0 & \frac{\sqrt{3}}{2} & -\frac{\sqrt{3}}{2}
\end{array}\right] \\
\mathbf{v}_{\alpha \beta}^{+} & =\left[T_{\alpha \beta}\right] \mathbf{v}_{a b c}^{+}=\left[T_{\alpha \beta}\right]\left[T_{+}\right] \mathbf{v}_{a b c} \\
& =\left[T_{\alpha \beta}\right]\left[T_{+}\right]\left[T_{\alpha \beta}\right]^{T} \mathbf{v}_{\alpha \beta}=\frac{1}{2}\left[\begin{array}{cc}
1 & -q \\
q & 1
\end{array}\right] \mathbf{v}_{\alpha \beta} \\
\mathbf{v}_{\alpha \beta}^{-} & =\left[T_{\alpha \beta}\right] \mathbf{v}_{a b c}^{-}=\left[T_{\alpha \beta}\right]\left[T_{-}\right] \mathbf{v}_{a b c} \\
& =\left[T_{\alpha \beta}\right]\left[T_{-}\right]\left[T_{\alpha \beta}\right]^{T} \mathbf{v}_{\alpha \beta}=\frac{1}{2}\left[\begin{array}{cc}
1 & q \\
-q & 1
\end{array}\right] \mathbf{v}_{\alpha \beta} .
\end{aligned}
$$

Since the SOGI-QSG behaves as a quadrature signal generator itself, the in-quadrature signals to be computed in (26) to calculate the instantaneous positive- and negative-sequence components of the three-phase input vector can be obtained by means of using a SOGI-QSG for each $\alpha$ and $\beta$ component of the 


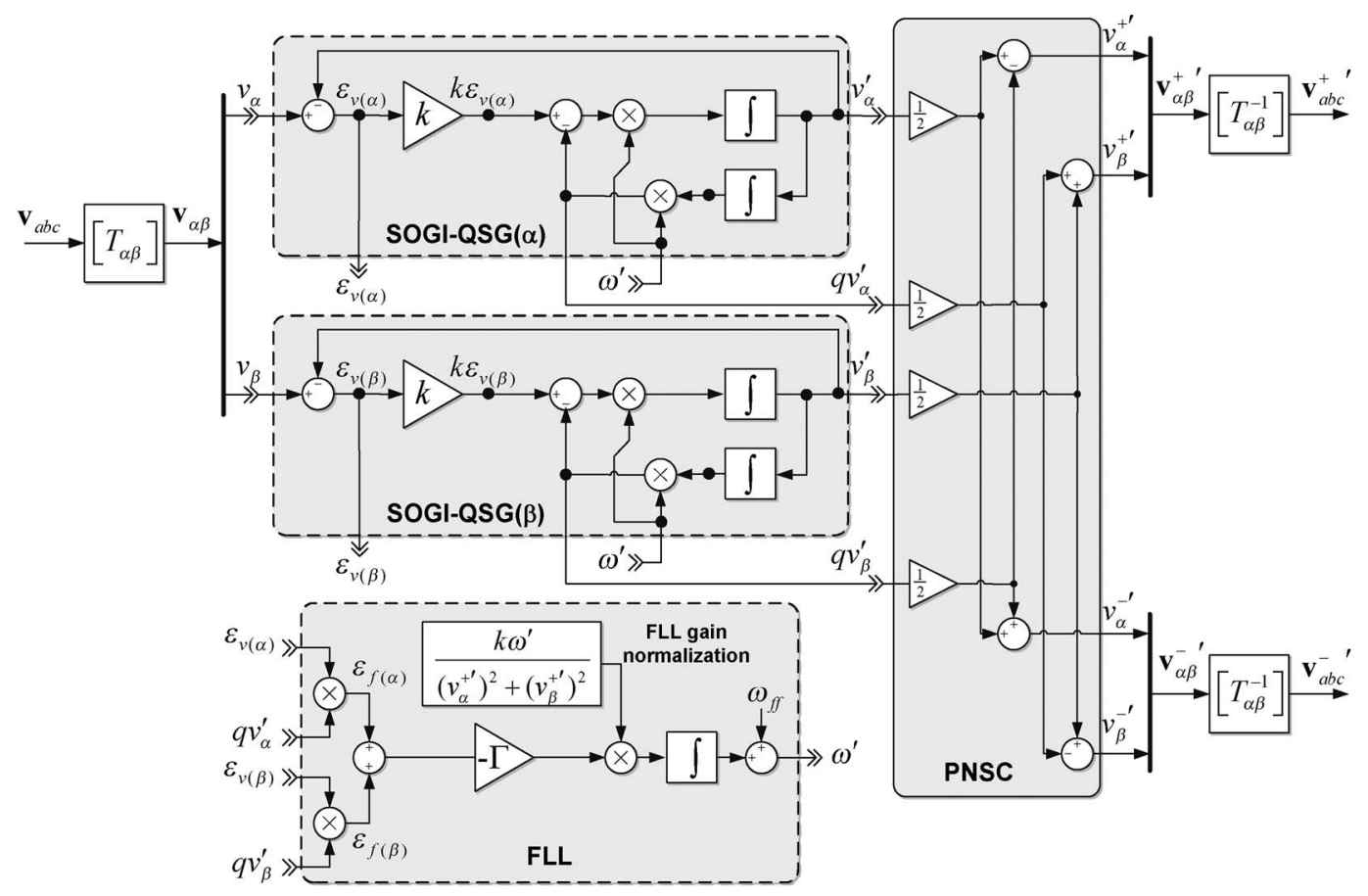

Fig. 10. Block diagram of the DSOGI-FLL divided into its building blocks: SOGI-QSG $(\beta)$, SOGI-QSG $(\alpha)$, FLL, and PNSC.

transformed input vector. This reasoning permits to obtain the synchronization structure in Fig. 10, which is able to detect the positive- and negative-sequence components of a three-phase input vector at a certain frequency $\omega^{\prime}$. In the system of Fig. 10, two SOGI-QSGs working on the $\alpha \beta$ stationary reference frame provide the input signals to a positive-/negative-sequence calculation block (PNSC), which implements the transformations in (26). This system was extensively discussed in [25] and named as dual SOGI-FLL (DSOGI-FLL).

Hence, if several DSOGI blocks are tuned at different harmonic frequencies and connected each other by using the cross-feedback network in Fig. 11 (HDN), a synchronization system able to detect multiple harmonic components from an unbalanced and distorted three-phase input voltage vector is obtained.

As it can be noticed in Fig. 11, the main structure of the threephase MSOGI-FLL is essentially the same as the one presented in Fig. 8 for single-phase systems. The FLL block detects the grid frequency by only using the fundamental frequency component of the input vector $\mathbf{v}_{1(\alpha \beta)}^{\prime}$. Later on, the detected value for the fundamental frequency is multiplied by the corresponding harmonic order to tune the rest of the DSOGI-QSGs. Moreover, the value of $k$ in each DSOGI-QSG is divided by the corresponding harmonic order to keep the product $k \omega^{\prime}$ constant, which guarantees the same bandwidth for all the DSOGI-QSGs.

\section{Simulation Results}

An unbalanced and highly distorted three-phase grid voltage was considered in simulation for demonstrating the excellent performance of the three-phase MSOGI-FLL. During the grid fault, the positive- and negative-sequence voltage phasors at the fundamental frequency were set to $\vec{V}^{+1}=0.5 \angle-30^{\circ}$ and $\vec{V}^{-1}=0.25 \angle 110^{\circ}$, where the prefault grid voltage is given by

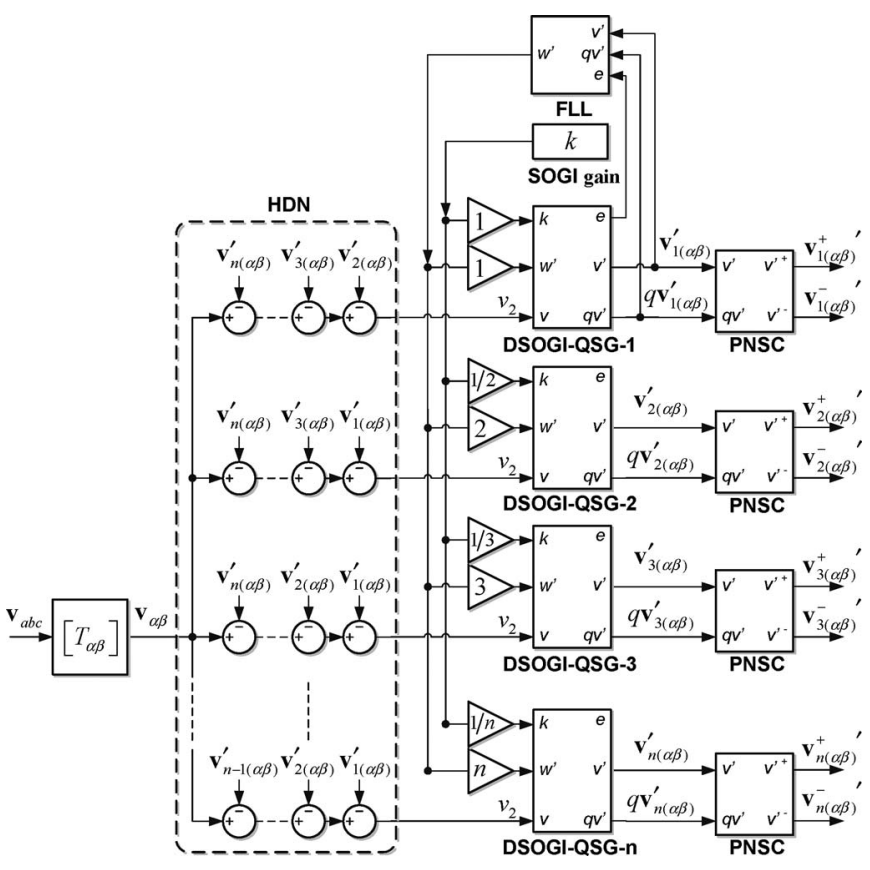

Fig. 11. MSOGI-FLL for three-phase systems able to synchronize with " $n$ " harmonic components of the input vector.

$\vec{V}_{p f}=1 \angle 0^{\circ}$. Regarding harmonics, they were set to $\vec{V}^{-5}=$ $0.2 \angle 0^{\circ}, \vec{V}^{+7}=0.2 \angle 0^{\circ}$, and $\vec{V}^{-11}=0.2 \angle 0^{\circ}$ for the fifth, seventh, and eleventh harmonics, respectively. Characteristic harmonics in multiples of three (zero sequence) were not considered in simulation since they would be cancelled out by the Clarke transformation of (15). Moreover, to set a more exigent scenario, a jump of the fundamental frequency from 50 to $45 \mathrm{~Hz}$ occurred during the simulated grid fault. Hence, the resulting unbalanced and distorted grid voltage considered in this study case is shown in Fig. 12. 


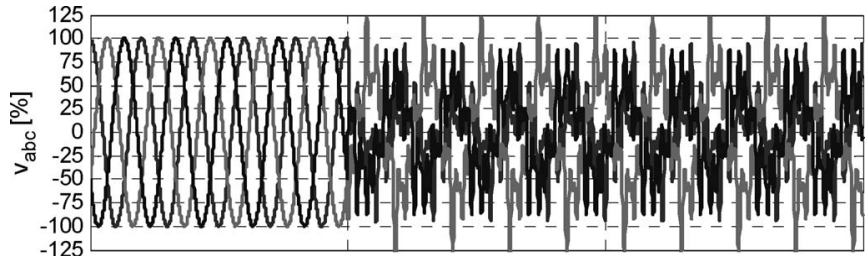

Fig. 12. Unbalanced and distorted grid voltage considered in this paper.
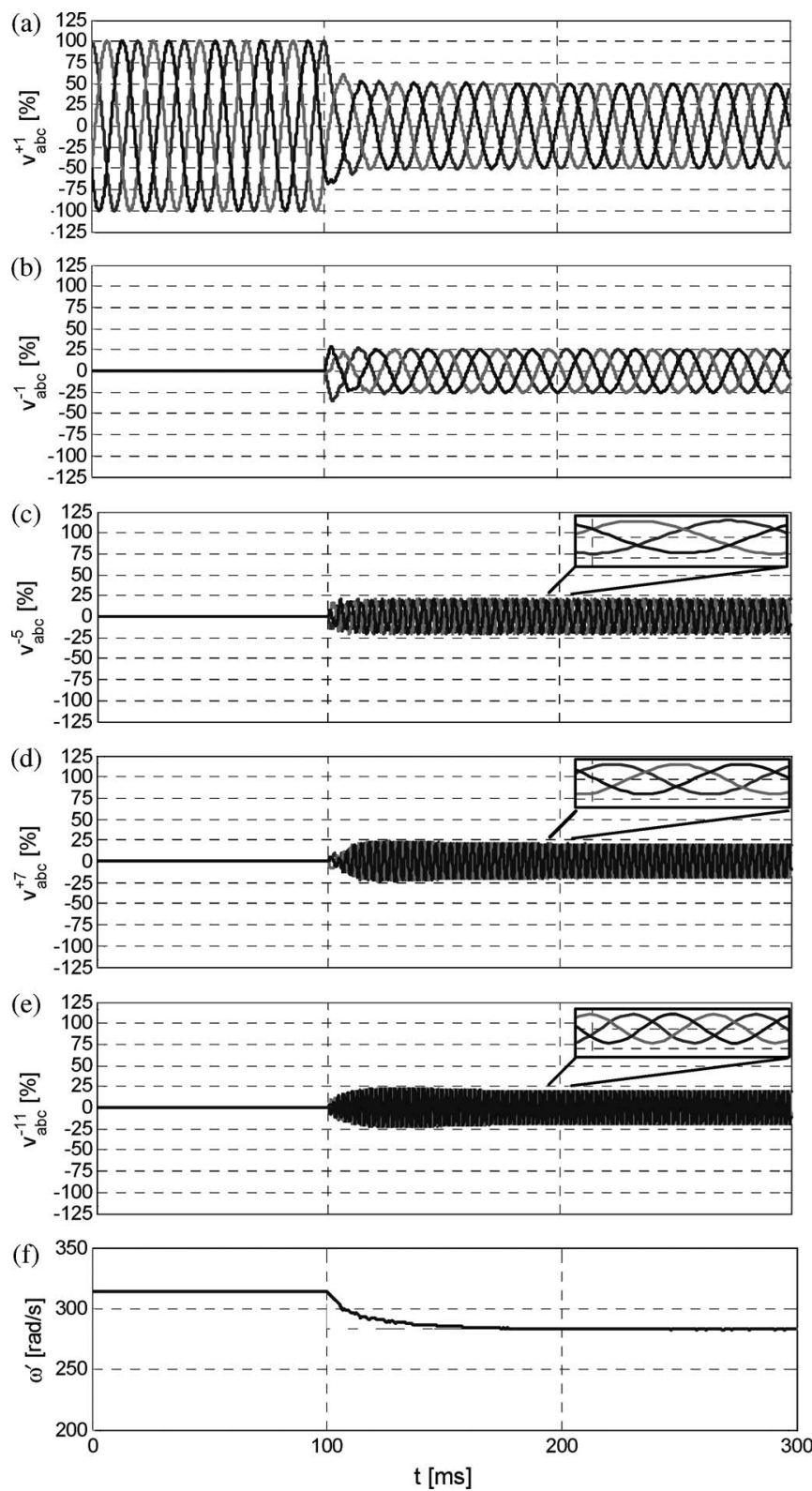

Fig. 13. Response of MSOGI-FLL.

The MSOGI-FLL of this simulation consisted of four individual SOGI-QSGs tuned at the first, fifth, seventh, and eleventh harmonics. The gain for the SOGI-QSG-1, tuned at the fundamental frequency, was set to $k_{1}=\sqrt{2}$, while the gain for the rest of the SOGI-QSGs was divided by the harmonic order to maintain the same filtering characteristic in all cases. Finally, the dc gain of the FLL was set to $\Gamma=50$.

Fig. 13 shows the simulation response of the MSOGI-FLL under the aforementioned extremely unbalanced and polluted
TABLE I

PARAMETERS OF INPUT VOLTAGE

\begin{tabular}{cc}
\hline Voltage component & Value [p.u.] \\
\hline Fundamental positive-sequence & $\vec{V}^{+1}=0.733 \angle 5^{\circ}$ \\
Fundamental negative-sequence & $\vec{V}^{+1}=0.210 \angle 50.4^{\circ}$ \\
$3^{\text {rd }}$ harmonic zero-sequence & $\vec{V}^{03}=0.10 \angle 45^{\circ}$ \\
$5^{\text {th }}$ harmonic negative-sequence & $\vec{V}^{-5}=0.25 \angle 45^{\circ}$ \\
$7^{\text {th }}$ harmonic positive-sequence & $\vec{V}^{+7}=0.20 \angle 180^{\circ}$ \\
$11^{\text {th }}$ harmonic negative-sequence & $\vec{V}^{-11}=0.15 \angle 180^{\circ}$ \\
$160 \mathrm{~Hz}$ interharmonic & $\vec{V}^{160 H z}=0.07 \angle-45^{\circ}$ \\
$20 \mathrm{~Hz}$ subharmonic & $\vec{V}^{20 H z}=0.05 \angle 0^{\circ}$ \\
\hline
\end{tabular}

grid conditions. The plots in Fig. 13(a) and (b) show how the estimation of the positive- and negative-sequence components is almost perfect and practically does not differ from the case when there were no harmonics on the grid voltage. In turn, Fig. 13(c)-(e) shows the accurate estimation of the instantaneous components for the fifth, seventh, and eleventh harmonics albeit the frequency jump experienced by the input voltage in the simulation.

It is worth noting at this point the fast and precise estimation of the harmonic components, obtaining both positive and negative sequences of each one, even under changing frequency conditions. These results cannot be obtained by using the conventional Fourier analysis, where the fundamental frequency of the input signal is assumed as a constant and wellknown magnitude. Finally, Fig. 13(f) shows the evolution of the detected fundamental grid frequency. It is possible to appreciate in this figure how the feedback-based linearization of the FLL works well even under hard distorted conditions, matching the settle time to that calculated by (11).

\section{EXPERIMENTAL RESUlts}

To experimentally validate the performance of the synchronization system presented in this paper, the algorithm of the MSOGI-FLL was implemented in a control board based on the floating-point DSP Texas Instruments TMS320F28335 at $150 \mathrm{MHz}$ (6.67-ns cycle time). The unbalanced and distorted input voltage was generated by means of an ac programmable source. The parameters of the unbalanced and distorted input voltage are described in Table I. As shown in this table, an interharmonic and a subharmonic have also been included in the testing signal. However, their value had been limited to a lower level, when compared with other harmonics, due to the fact that they hardly appear with high amplitude in actual distribution networks.

\section{A. Estimation of Harmonics}

Fig. 14 shows the experimental results recorded from the control board by using the pulse-width-modulation outputs and low-pass filters as digital-to-analog converters, as reported in [43]. Fig. 14(a) shows the input voltage, which was unbalanced and extremely distorted. Fig. 14(b) and (c) shows the waveforms estimated by MSOGI for the positive- and negativesequence components at the fundamental frequency. Likewise, the instantaneous values for the fifth, seventh, and eleventh 


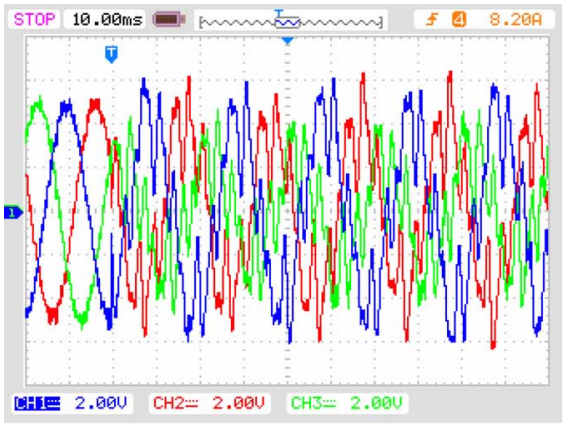

(a)

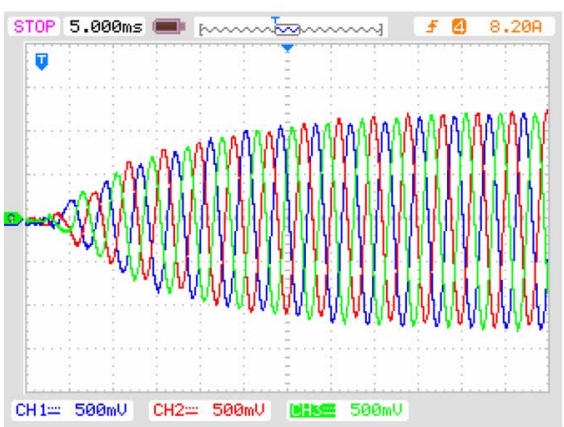

(d)

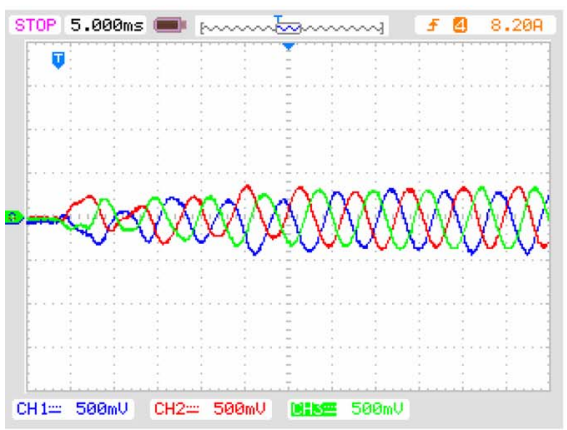

(g)

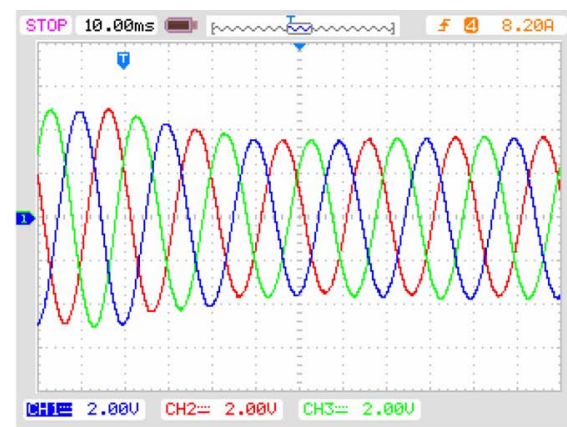

(b)

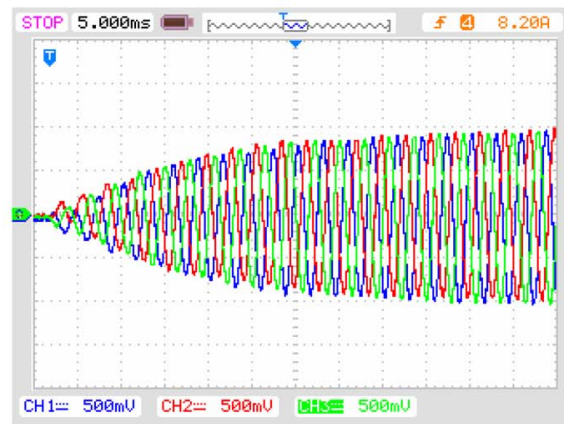

(e)

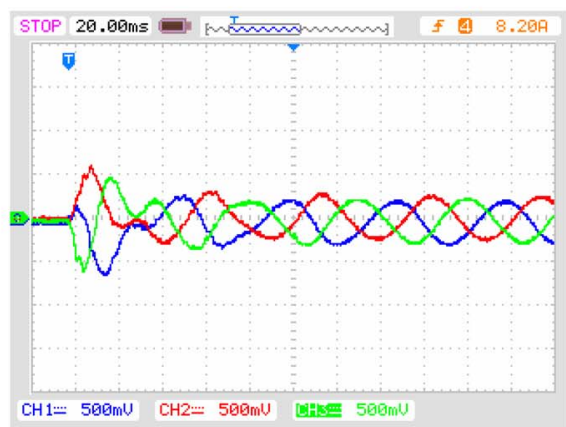

(h)

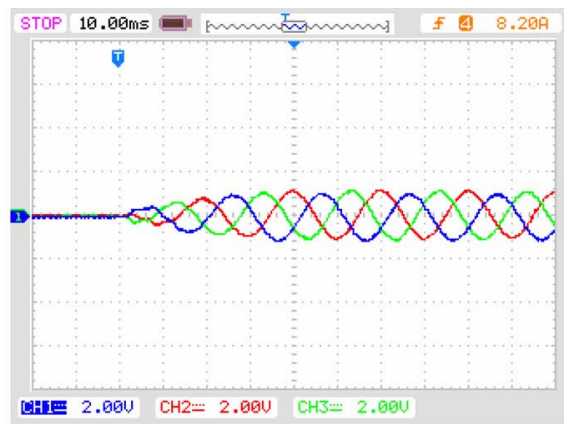

(c)

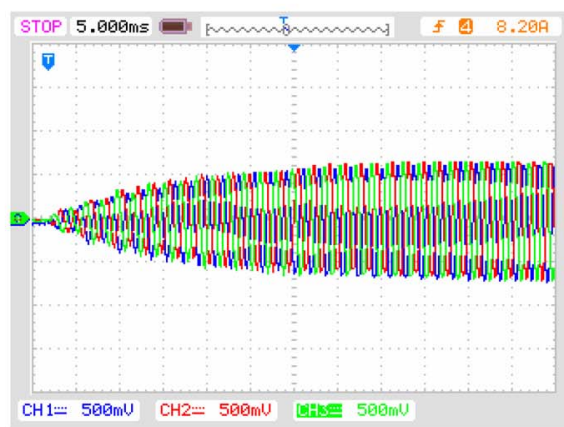

(f)

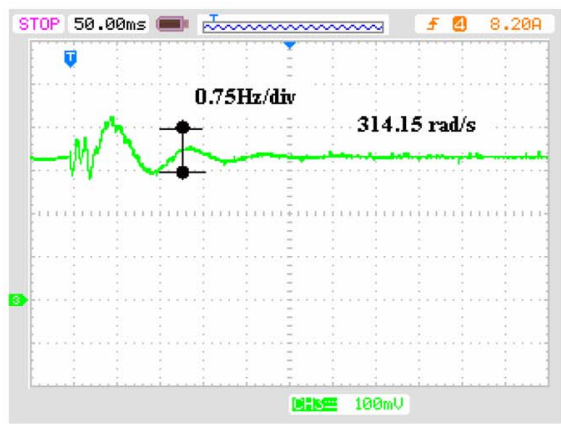

(i)

Fig. 14. MSOGI-FLL experimental estimation of harmonic components. (a) Input signal (40 V/div-10 ms/div). (b) $50-\mathrm{Hz}$ positive sequence (40 V/div$10 \mathrm{~ms} / \mathrm{div})$. (c) $50-\mathrm{Hz}$ negative sequence (40 V/div-10 ms/div). (d) Fifth harmonic (10 V/div-5 ms/div). (e) Seventh harmonic (10 V/div-5 ms/div). (f) Eleventh harmonic (10 V/div-5 ms/div). (g) $160-\mathrm{Hz}$ interharmonic (10 V/div-5 ms/div). (h) $20-\mathrm{Hz}$ subharmonic (10 V/div-20 ms/div). (i) Frequency estimation $(0.75 \mathrm{~Hz} / \mathrm{div}-50 \mathrm{~ms} / \mathrm{div})$.

harmonics are depicted in Fig. 14(d)-(f). In these plots, for the sake of clarity, the time scale and the V/div ratio had been reduced. The estimations of the $160-\mathrm{Hz}$ interharmonic and the 20-Hz subharmonic are shown in Fig. 14(g) and (h), respectively. Finally, the value of the frequency detected by the MSOGI-FLL is displayed in Fig. 14(i). According to the results shown in Fig. 14, the good performance of the MSOGI-FLL has been demonstrated.

In this test, the third harmonic is not shown, since their influence was cancelled out due to the Clarke transformation applied at the MSOGI. Considering the application of MSOGI in threephase three-wire networks, this feature is an advantage due to the fact that no action can be performed with a power converter in these networks to counteract such current harmonics; hence, it is not needed to be detected.

To evidence even more the benefits of the harmonic multiresonant structure of the MSOGI-FLL, the unbalanced and distorted voltage in Fig. 14 was applied to the input of a DSOGI-FLL in Fig. 10, which was proven in [25] to be a very suitable solution for synchronizing with unbalanced grids. The
DSOGI-PLL algorithm was also programmed in the control system previously described, and all the settings were kept unaltered for this second experiment [44].

Fig. 15 shows some plots regarding the amplitudes for the positive- and negative-sequence components detected by the DSOGI-FLL, which does not have any cross-feedback network. As it can be appreciated in Fig. 15(a) and (b), the inherent filtering characteristic of the DSOGI-FLL is not selective enough to cancel out the effect of the harmonic components when the input voltage is highly polluted. Moreover, the estimation of the frequency that is necessary for tuning the DSOGI contains harmonics, giving rise to a steady $1.5 \mathrm{~Hz}$ ripple, as shown in Fig. 15(c).

Consequently, the detected waveforms are affected by a notable distortion. This distortion is higher in the negativesequence component due to the high fifth harmonic content in the input. Although the DSOGI-FLL filtering can be improved, there is a tradeoff between filtering capability and dynamical response, as demonstrated previously; something that can be overcame using MSOGI-FLL. 
(a)

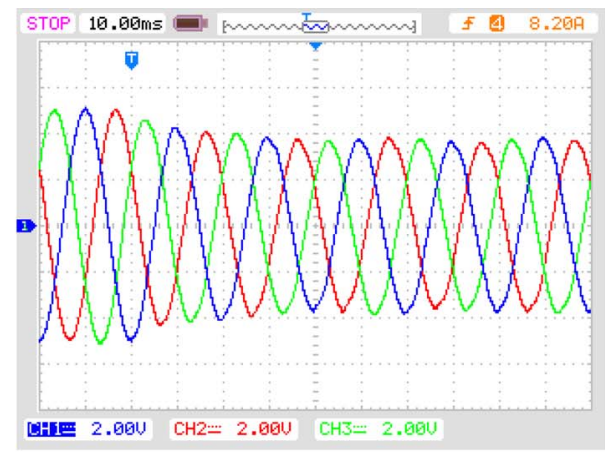

(b)

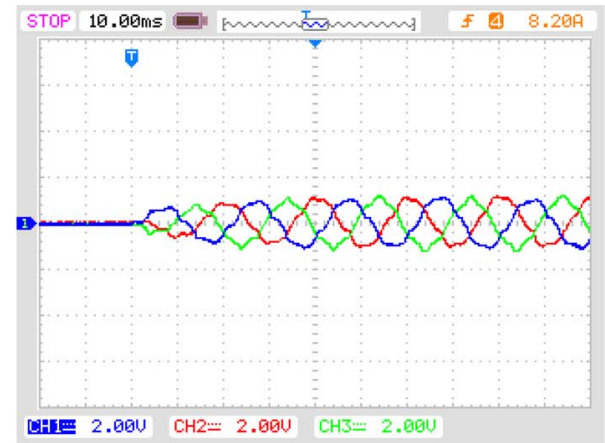

(c)

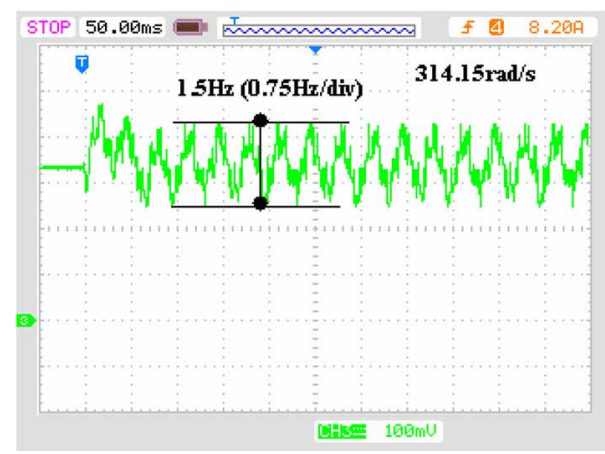

Fig. 15. Experimental response of DSOGI-FLL under distorted voltage. (a) $50-\mathrm{Hz}$ positive sequence $(40 \mathrm{~V} / \mathrm{div}-10 \mathrm{~ms} / \mathrm{div})$. (b) $50-\mathrm{Hz}$ negative sequence (40 V/div-10 ms/div). (c) Frequency estimation $(0.75 \mathrm{~Hz} / \mathrm{div}-50 \mathrm{~ms} / \mathrm{div})$.

\section{B. Burden Time}

In this paper, the MSOGI-FLL was implemented using seven embedded DSOGIs (one per each harmonic plus the fundamental one). The sampling frequency was set to $10 \mathrm{kHz}$, and the computational cost of the whole MSOGI-FLL took $26 \mu$ s. The DSOGI used for estimating the fundamental component was computed in $4.26 \mu \mathrm{s}$, including the PNSC. On the other hand, the DSOGI blocks used for the rest of the harmonics were calculated in $3 \mu \mathrm{s}$. This difference in burden time lies on the fact that a higher-order discretization is needed for the $50-\mathrm{Hz}$ block to avoid delays in the loop that could be harmful due its connection with the FLL block.

In turn, the single FLL took $1.65 \mu$ s and the cross-feedback HDN took $2.087 \mu$ s.

Within this period, the MSOGI algorithm estimates the instantaneous positive/negative sequence of seven harmonics, hence 42 signals. If the same test was performed using a discrete Fourier transform (DFT)-based algorithm, then it would be necessary to apply the DFT 42 times, one for each harmonic/ phase, giving rise to a higher burden time. In addition, the fast Fourier transform (FFT) cannot directly be used under frequency-variable conditions as it needs to acquire a buffer of signals equal to exact multiples or submultiples of every cycle of the fundamental component.

Therefore, and considering the high number of characteristic values estimated by the MSOGI-FLL in this paper, using around $25 \%$ of the control step $(100 \mu \mathrm{s})$ to process the synchronization algorithm is considered a good result, as there is still enough time left to implement the controllers for grid-connected power converters and the rest of the realtime functionalities of the low-level control algorithm. Moreover, the experimental platform used in these experiments is based on a DSP designed for industrial applications and not specifically oriented to signal processing applications. Obviously, the burden time would dramatically be reduced if a field-programmable gate array or a high-performance DSP was used.

The satisfactory response of the proposed MSOGI-FLL when programmed in a standard DSP, together with its low computational burden, makes this synchronization system a very suitable solution to be applied in real-time controllers of power converters connected to the grid.

\section{CONCLUSION}

A new concept in the grid synchronization of power converters for three-phase systems under unbalanced and distorted operating conditions, i.e., the MSOGI-FLL, has been introduced in this paper. The MSOGI-FLL consists of multiple DSOGIs tuned at different harmonics of the fundamental grid frequency. These DSOGIs work in a collaborative way by using a crossfeedback network, i.e., the HDN, which allows decoupling the effect of the different harmonics of the sensed voltage on the input signals of each DSOGI.

The MSOGI-FLL allows detecting the positive and negative components of each harmonic of the measured grid voltage under extremely polluted conditions, even in variable-frequency scenarios, something that cannot be achieved by using the conventional FFT algorithm.

The resulting MSOGI-FLL is a frequency-adaptive algorithm thanks to the FLL block, which permits detecting the fundamental frequency of the input signals. The fact that the MSOGIFLL is based on the estimation of the grid voltage frequency, and not the grid voltage phase angle, results in an additional advantage if compared with other advanced PLLs, since the grid frequency variable is more stable than the voltage phase angle during transient faults.

The MSOGI-FLL does not process any trigonometric function since neither SRFs nor conventional voltage-controlled oscillators are used in its algorithm. This feature contributes to reducing the computation time, finally getting a low computational burden algorithm.

Simulations, together with an experimental evaluation, were presented in this paper to demonstrate that the MSOGI-FLL is a very suitable solution for accurately detecting the fundamentalfrequency positive- and negative-sequence components of the grid voltage, as well as its relevant harmonics, under highly unbalanced and distorted grid conditions. 


\section{REFERENCES}

[1] European Commission-Office for Official Publications of the European Communities, Towards Smart Power Networks-Lessons Learned From European Research FP5 Projects, Ref. EUR 21970, Luxembourg, 2005.

[2] F. Blaabjerg, Z. Chen, and S. B. Kjaer, "Power electronics as efficient interface in dispersed power generation systems," IEEE Trans. Power Electron., vol. 19, no. 5, pp. 1184-1194, Sep. 2004.

[3] P. Rioual, H. Pouliquen, and J. P. Louis, "Regulation of a PWM rectifier in the unbalanced network state using a generalized model," IEEE Trans. Power Electron., vol. 11, no. 3, pp. 495-502, May 1996.

[4] M. Bongiorno and J. Svensson, "Voltage dip mitigation using shuntconnected voltage source converter," IEEE Trans. Power Electron., vol. 22, no. 5, pp. 1867-1874, Sep. 2007.

[5] D. Santos-Martin, J. L. Rodriguez-Amenedo, and S. Arnaltes, "Direct power control applied to doubly fed induction generator under unbalanced grid voltage conditions," IEEE Trans. Power Electron., vol. 23, no. 5, pp. 2328-2336, Sep. 2008.

[6] J. Eloy-Garcia, S. Arnaltes, and J. L. Rodriguez-Amenedo, "Direct power control of voltage source inverters with unbalanced grid voltages," IET Power Electron., vol. 1, no. 3, pp. 395-407, Sep. 2008.

[7] J. Yao, H. Li, Y. Liao, and Z. Chen, "An improved control strategy of limiting the DC-link voltage fluctuation for a doubly fed induction wind generator," IEEE Trans. Power Electron., vol. 23, no. 3, pp. 1205-1213, May 2008.

[8] P. Rodriguez, A. V. Timbus, R. Teodorescu, M. Liserre, and F. Blaabjerg, "Flexible active power control of distributed power generation systems during grid faults," IEEE Trans. Ind. Electron., vol. 54, no. 5, pp. 25832592 , Oct. 2007.

[9] S. Alepuz, S. Busquets-Monge, J. Bordonau, J. A. Martinez-Velasco, C. A. Silva, J. Pontt, and J. Rodriguez, "Control strategies based on symmetrical components for grid-connected converters under voltage dips," IEEE Trans. Ind. Electron., vol. 56, no. 6, pp. 2162-2173, Jun. 2009.

[10] M. Malinowski, S. Stynski, W. Kolomyjski, and M. Kazmierkowski, "Control of three-level PWM converter applied to variable-speed-type wind turbines," IEEE Trans. Ind. Electron., vol. 56, no. 1, pp. 69-77, Jan. 2009.

[11] A. Fradkov, I. Junussov, and R. Ortega, "Decentralized adaptive synchronization in nonlinear dynamical networks with nonidentical nodes," in Proc. IEEE CCA/ISIC, Jul. 8-10, 2009, pp. 531-536.

[12] S. Shinnaka, "A robust single-phase PLL system with stable and fast tracking," IEEE Trans. Ind. Appl., vol. 44, no. 2, pp. 624-633, Mar./Apr. 2008.

[13] L. Chen, J. Lu, and C. K. Tse, "Synchronization: An obstacle to identification of network topology," IEEE Trans. Circuits Syst. II, Exp. Briefs, vol. 56, no. 4, pp. 310-314, Apr. 2009.

[14] L. Jinling, Z. Wang, Y. Liu, and X. Liu, "Global synchronization control of general delayed discrete-time networks with stochastic coupling and disturbances," IEEE Trans. Syst., Man, Cybern. B, Cybern., vol. 38, no. 4, pp. 1073-1083, Aug. 2008.

[15] S. Chung, "A phase tracking system for three phase utility interface inverters," IEEE Trans. Power Electron., vol. 15, no. 3, pp. 431-438, May 2000.

[16] M. A. Perez, J. R. Espinoza, L. A. Moran, M. A. Torres, and E. A. Araya, "A robust phase-locked loop algorithm to synchronize static-power converters with polluted AC systems," IEEE Trans. Power Electron., vol. 55, no. 5, pp. 2185-2192, May 2008

[17] P. Li, L. Xue, P. Hazucha, T. Karnik, and R. Bashirullah, "A delaylocked loop synchronization scheme for high-frequency multiphase hysteretic DC-DC converters," IEEE J. Solid-State Circuits, vol. 44, no. 11, pp. 3131-3145, Nov. 2009.

[18] F. Blaabjerg, R. Teodorescu, M. Liserre, and A. V. Timbus, "Overview of control and grid synchronization for distributed power generation systems," IEEE Trans. Ind. Electron., vol. 53, no. 5, pp. 1398-1409, Oct. 2006.

[19] P. R. M. Santos Filho, P. F. Seixas, P. C. Cortizo, L. Torres, and A. F. Souza, "Comparison of three single-phase PLL algorithms for UPS applications," IEEE Trans. Ind. Electron., vol. 55, no. 8, pp. 2923-2932, Aug. 2008.

[20] M. H. J. Bollen, Understanding Power Quality Problems: Voltage Sags and Interruptions. New York: IEEE Press, 1999.

[21] P. Rodriguez, J. Pou, J. Bergas, J. I. Candela, R. P. Burgos, and D. Boroyevich, "Decoupled double synchronous reference frame PLL for power converters control," IEEE Trans. Power Electron., vol. 22, no. 2, pp. 584-592, Mar. 2007.

[22] M. Karimi-Ghartemani and M. R. Iravani, "A method for synchronization of power electronic converters in polluted and variable-frequency environments," IEEE Trans. Power Syst., vol. 19, no. 3, pp. 1263-1270, Aug. 2004.

[23] M. Karimi-Ghartemani and H. Karimi, "Processing of symmetrical components in time-domain," IEEE Trans. Power Syst., vol. 22, no. 2, pp. 572 579, May 2007

[24] M. Karimi-Ghartemani, H. Karimi, and A. Bakhshai, "A filtering technique for three-phase power system applications," IEEE Trans. Instrum. Meas., vol. 58, no. 2, pp. 389-396, Feb. 2009.

[25] P. Rodriguez, A. Luna, M. Ciobotaru, R. Teodorescu, and F. Blaabjerg, "Advanced grid synchronization system for power converters under unbalanced and distorted operating conditions," in Proc. 32nd Annи. Conf. IEEE Ind. Electron., Nov. 2006, pp. 5173-5178.

[26] V. M. Moreno, M. Liserre, A. Pigazo, and A. Dell'Aquila, "A comparative analysis of real-time algorithms for power signal decomposition in multiple synchronous reference frames," IEEE Trans. Power Electron., vol. 22, no. 4, pp. 1280-1289, Jul. 2007

[27] L. Asiminoaei, F. Blaabjerg, and S. Hansen, "Detection is key-Harmonic detection methods for active power filter applications," IEEE Ind. Appl. Mag., vol. 13, no. 4, pp. 22-33, Jul./Aug. 2007.

[28] M. Mojiri, M. Karimi-Ghartemani, and A. Bakhshai, "Time-domain signal analysis using adaptive notch filter," IEEE Trans. Signal Process. vol. 55, no. 1, pp. 85-93, Jan. 2007.

[29] D. Yazdani, A. Bakhshai, G. Joos, and M. Mojiri, "A nonlinear adaptive synchronization technique for grid-connected distributed energy sources," IEEE Trans. Power Electron., vol. 23, no. 4, pp. 2181-2186, Jul. 2008.

[30] D. Yazdani, A. Bakhshai, G. Joos, and M. Mojiri, "A real-time extraction of harmonic and reactive current in a nonlinear load for grid-connected converters," IEEE Trans. Ind. Electron., vol. 56, no. 6, pp. 2185-2189, Jun. 2009.

[31] D. Yazdani, M. Mojiri, A. Bakhshai, and G. Joos, "A fast and accurate synchronization technique for extraction of symmetrical components," IEEE Trans. Power Electron., vol. 24, no. 3, pp. 674-684, Mar. 2009.

[32] X. Yuan, W. Merk, H. Stemmler, and J. Allmeling, "Stationary frame generalized integrators for current control of active power filters with zero steady-state error for current harmonics of concern under unbalanced and distorted operating conditions," IEEE Trans. Ind. Appl., vol. 38, no. 2 , pp. 523-532, Mar./Apr. 2002.

[33] R. Teodorescu, F. Blaabjerg, M. Liserre, and P. C. Loh, "Proportionalresonant controllers and filters for grid-connected voltage-source converters," Proc. Inst. Elect. Eng.-Elect. Power Appl., vol. 153, no. 5, pp. 750-762, Sep. 2006.

[34] M. Liserre, R. Teodorescu, and F. Blaabjerg, "Multiple harmonics control for three-phase grid converter systems with the use of PI-RES current controller in a rotating frame," IEEE Trans. Power Electron., vol. 21, no. 3, pp. 836-841, May 2006

[35] J. Hu, Y. He, L. Xu, and B. W. Williams, "Improved control of DFIG systems during network unbalance using PI-R current regulators," IEEE Trans. Ind. Electron., vol. 56, no. 2, pp. 439-451, Feb. 2009.

[36] L. Asiminoaei, E. Aeloiza, P. N. Enjeti, and F. Blaabjerg, "Shunt activepower-filter topology based on parallel interleaved inverters," IEEE Trans. Ind. Electron., vol. 55, no. 3, pp. 1175-1189, Mar. 2008.

[37] K. de Brabandere, T. Loix, K. Engelen, B. Bolsens, J. Van den Keybus, J. Driesen, and R. Belmans, "Design and operation of a phase-locked loop with Kalman estimator-based filter for single-phase applications," in Proc. 32th Annu. Conf. IEEE Ind. Electron., Nov. 2006, pp. 525-530.

[38] P. Rodriguez, R. Teodorescu, I. Candela, A. V. Timbus, M. Liserre, and F. Blaabjerg, "New positive-sequence voltage detector for grid synchronization of power converters under faulty grid conditions," in Proc. IEEE PESC, Jun. 2006, pp. 1-7.

[39] M. Ciobotaru, R. Teodorescu, and F. Blaabjerg, "A new single-phase PLL structure based on second order generalized integrator," in Proc. IEEE PESC, Jun. 2006, pp. 1-7.

[40] P. Rodriguez, A. Luna, I. Candela, R. Teodorescu, and F. Blaabjerg, "Grid synchronization of power converters using multiple second order generalized integrators," in Proc. 34th Annu. Conf. IEEE Ind. Electron., Nov. $10-13,2008$, pp. $755-760$.

[41] C. L. Fortescue, "Method of symmetrical coordinates applied to the solution of polyphase networks," Trans. AIEE, vol. 37, no. II, pp. 1027-1140, 1918

[42] W. V. Lyon, Application of the Method of Symmetrical Components. New York: McGraw-Hill, 1937.

[43] D. M. Alter, "Using PWM output as a digital-to-analog converter on a TMS320F280X digital signal controller," Texas Instruments, Dallas, TX, Application Report SPAA88, Feb. 2006.

[44] L. Harnefors, "Implementation of resonant controllers and filters in fixedpoint arithmetic," IEEE Trans. Ind. Electron., vol. 56, no. 4, pp. 1273 1281, Apr. 2009 


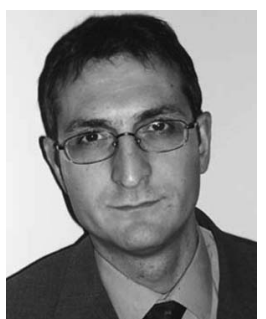

Pedro Rodríguez (S'99-M'04-SM'10) received the B.S. degree in electrical engineering from the University of Granada, Granada, Spain, in 1989, and the M.S. and Ph.D. degrees in electrical engineering from the Technical University of Catalonia (UPC), Barcelona, Spain, in 1994 and 2004, respectively.

He was an Assistant Professor in 1990 and an Associate Professor in 1993 with UPC. He was a Researcher with the Center for Power Electronics Systems, Virginia Polytechnic Institute and State University, Blacksburg, and the Institute of Energy Technology, Aalborg University, Aalborg, Denmark, in 2005 and 2006, respectively. He is currently the Head of the Research Group on renewable electrical energy systems with the Department of Electrical Engineering, UPC. He has coauthored about 100 papers in technical journals and conferences. He is the holder of five patents. His research interests include integration of distributed energy systems, power conditioning, and control of power converters.

Dr. Rodríguez is a member of the IEEE Power Electronics, the IEEE Industrial Electronics, the IEEE Industry Application Societies, and the IEEEIES Technical Committee on Renewable Energy Systems. He has coorganized special sessions in several IEEE conferences on power electronics applied to renewable energies. He is an Associate Editor of the IEEE TRANSACTIONS on Power Electronics and the Committee Chair of the IEEE-IES Gold and Student Activities.

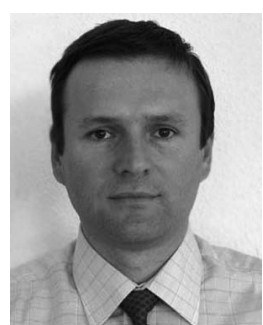

Remus Teodorescu (S'96-A'97-M'99-SM'02) received the Dipl. Ing. degree in electrical engineering from the Polytechnical University of Bucharest, Bucharest, Romania, in 1989, and the Ph.D. degree in power electronics from the University of Galati, Galati, Romania, in 1994

From 1989 to 1990, he was with Iron and Steel Plant Galati. He then moved to the Department of Electrical Engineering, University of Galati, where he was an Assistant and has been an Assistant Professor since 1994. In 1996, he was appointed Head of the Power Electronics Research Group, University of Galati. In 1998, he joined the Power Electronics and Drives Department, Institute of Energy Technology, Aalborg University, Aalborg, Denmark, where he is currently a Full Professor. $\mathrm{He}$ is the coordinator of Vestas Power Program, a research project between Vestas Wind Systems A/S and Aalborg University in power electronics, power systems and energy storage areas. He has published more than 180 technical papers, two books, and five patents.

Dr. Teodorescu is an Associate Editor for the IEEE TRANSACTIONS ON Power Electronics LetTers and the Chair of the IEEE Danish Industry Applications Society (IAS)/Industrial Electronics Society (IES)/Power Electronics Society (PELS) chapter. He is the corecipient of the Technical Committee Prize Paper Award from the IEEE IAS Annual Meeting 1998 and the Third-ABB Prize Paper Award from IEEE Optim 2002.

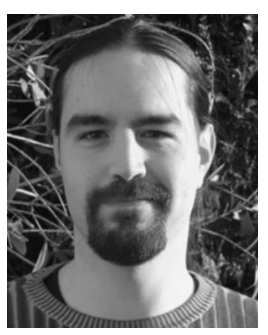

Alvaro Luna (S'07) received the B.Sc., M.Sc., and $\mathrm{Ph} . \mathrm{D}$. degrees in electrical engineering from the Universitat Politecnica de Catalunya (UPC), Barcelona, Spain, in 2001, 2005, and 2009, respectively.

Since 2005, he has been with UPC, where he is currently an Assistant Professor. His research interests include wind turbines control, integration of distributed generation, and power conditioning.

Dr. Luna is a Student Member of the IEEE Power Electronics Society, the IEEE Industrial Electronics Society, and the IEEE Industrial Applications Society.

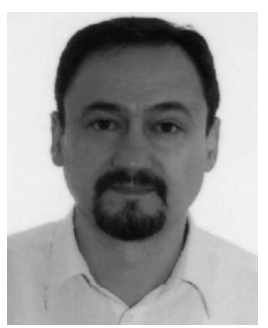

Ignacio Candela (S'99-M'04) received the B.S., M.S., and Ph.D. degrees from the Technical University of Catalonia (UPC), Barcelona, Spain, in 1987, 2000, and 2009, respectively, all in industrial engineering.

He was an Assistant Professor in 1991 and has been an Associate Professor since 1993 with UPC. $\mathrm{He}$ has authored or coauthored more than 30 published technical papers and has been involved in several industrial projects and educational programs in the fields of power quality conditioning and motor drives. His current research interests include power conditioning, integration of distributed energy systems, and control of power converters and motor drives.

Dr. Candela is a member of the IEEE Power Electronics Society, the IEEE Industrial Electronics Society, and the IEEE Industry Application Society.

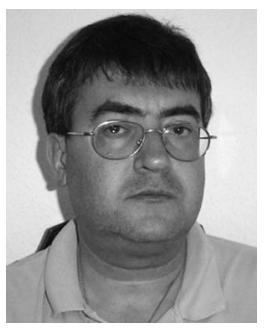

Ramon Mujal (S'99-M'04) received the B.S. and $\mathrm{Ph} . \mathrm{D}$. degrees in electrical engineering from the Technical University of Catalonia (UPC), Barcelona, Spain, in 1993 and 2004, respectively.

$\mathrm{He}$ is a currently an Assistant Professor with the Department of Electrical Engineering, UPC. He has authored several books in the field of circuits and measurement and power systems. His research interests include electrical machine renewable electrical energy systems, particularly wind power.

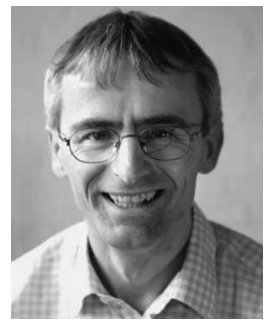

Frede Blaabjerg (S'86-M'88-SM'97-F'03) was born in Erslev, Denmark, on May 6, 1963. He received the M.Sc.E.E. and Ph.D. degrees from Aalborg University, Aalborg East, Denmark, in 1987 and 1995, respectively.

From 1987 to 1988 , he was with ABB-Scandia, Randers, Denmark. In 2000, he was a Visiting Professor with the University of Padova, Padova, Italy, as well as part-time Program Research Leader in wind turbines with the Research Center Risoe, Risoe, Italy. In 2002, he was a Visiting Professor with the Curtin University of Technology, Perth, Australia. He is currently a Full Professor in power electronics and drives and the Dean of the Faculty of Engineering and Science, Aalborg University. He is involved in more than 15 research projects within the industry, including the Danfoss Professor Program in power electronics and drives. He is the author or coauthor of more than 350 publications in his research fields, including the book Control in Power Electronics (New York: Academic, 2002). He is an Associate Editor for the Journal of Power Electronics and for Elteknik. His research areas are in power electronics, static power converters, ac drives, switched reluctance drives, modeling, characterization of power semiconductor devices and simulation, power quality, wind turbines, and green power inverters.

Dr. Blaabjerg received the 1995 Angelos Award for his contribution in modulation technique and control of electric drives, the Annual Teacher Prize from Aalborg University in 1995, the Outstanding Young Power Electronics Engineer Award from the IEEE Power Electronics Society in 1998, five IEEE Prize Paper Awards during the last six years, the C. Y. O'Connor Fellowship from Perth, Australia in 2002, the Statoil-Prize for his contributions in Power Electronics in 2003, and the Grundfos Prize in acknowledgment of his international scientific research in power electronics in 2004. In 2007, he was awarded Knight of the Order of Dannebrog by Her Majesty, Queen Margrethe II of Denmark. He has been an Associate Editor of the IEEE TRANSACTIONS ON INDUSTRY APPLICATIONS and is currently the Editorin-Chief of the IEEE TRANSACTIONS ON POWER Electronics. He is a member of the European Power Electronics and Drives Association, the IEEE Industry Applications Society Industrial Drives Committee, the Industry Power Converter Committee, and the Power Electronics Devices and Components Committee, IEEE Industry Application Society. He has served as member of the Danish Technical Research Council in Denmark from 1997 to 2003, and from 2001 to 2003, he was the Chairman. He has also been the Chairman of the Danish Small Satellite Program and the Center Contract Committee. He became a member of the Danish Academy of Technical Science in 2001, and in 2003, he became a member of the Academic Council. From 2002 to 2003, he was a member of the Board of the Danish Research Councils. In 2004, he became the Chairman of the Program Committee on Energy and Environment. 